\title{
2 AGUA YTERRITORIO \\ Territorialidades en conflicto y acciones colectivas: las luchas por el agua en Sierras Chicas, provincia de Córdoba, Argentina
}

\section{Territorialities in conflict and collective actions: The struggle for water in Sierras Chicas, Córdoba, Argentina}

Sergio Chiavassa

Universidad Nacional de Córdoba Córdoba, Argentina sachapig@yahoo.com.ar

Beatriz Ensabella Universidad Nacional de Córdoba Córdoba, Argentina bettyensabella@gmail.com

J oaquín Ulises Deón Universidad Nacional de Córdoba Córdoba, Argentina

joaquinudeon@yahoo.com.ar

Resumen - Las localidades ubicadas en el faldeo oriental de las Sierras Chicas de Córdoba, sufren cíclicamente crisis por insuficiencia hídrica y también inundaciones. En este escenario, se vienen planteando situaciones conflictivas entre diversos agentes sociales con intereses contrapuestos en torno al agua, el uso del suelo y el bosque. La situación ha provocado movilizaciones vecinales que requieren de un análisis territorial en el abordaje de los conflictos ambientales. El artículo propone analizar las acciones colectivas de las organizaciones sociales de Sierras Chicas de Córdoba que vienen trabajando en torno a las problemáticas ambientales regionales. Para ello, analizamos las cuencas como territorios y abrimos el debate sobre recursos naturales y bienes comunes de la naturaleza. Siguiendo a Escobar (2010) y Babiano-Amelibia (2015) el propósito último es pensar en posibilidades de construir otros modelos de democracia y otras alternativas al desarrollo centradas en las lógicas del lugar.

Abstract - Water The area around the eastern slope of Sierras Chicas, Córdoba, experiences a periodic hydrological crisis stemming from both a lack of water as well as floods. This context has generated conflictive situations between different social agents with competing interests in water, land use and woodlands. The situation has induced local mobilizations that require a territorial analysis of the environmental conflicts. The article proposes to analyze the collective actions of the social organizations in Sierras Chicas that have been working on regional environmental issues. To this end, we analyze the basins as territories and open the debate on natural resources and nature's common property. Our goal is to brainstorm possible ways to build other models of democracy and development alternatives focused on the logic of place.

Palabras clave: territorio, organizaciones sociales, conflictos ambientales, Argentina Keywords: territory, social organizations, environmental conflicts, Argentina

Información Artículo: Recibido: 14 marzo 2016

Revisado: 15 enero 2017 


\section{INTRODUCCIÓN ${ }^{1}$}

Las localidades ubicadas en el faldeo oriental de las Sierras Chicas, en la provincia de Córdoba, Argentina, sufren cíclicamente problemas ambientales severos, vinculados sobre todo con las crisis por insuficiencia hídrica y su contracara, las catastróficas inundaciones, procesos desencadenados como parte de la historia de estos territorios-cuenca.

En este escenario, se plantean -a nivel localdisputas no solo por el agua, sino también por el uso del suelo y el bosque, y situaciones conflictivas entre los diversos agentes sociales. La falta de agua, así como el exceso y las destrucciones por los desbordes de ríos y arroyos, ha provocado movilizaciones vecinales que requieren de un análisis socio-territorial tendente al logro de una solución colectiva a los problemas.

Las comunidades locales, vienen llevando adelante desde hace varios años, una serie de actividades que recién en los últimos tiempos están empezando a ser más organizadas y regulares. Es por ello que el presente artículo gira en torno al análisis de las acciones colectivas de estas organizaciones sociales que vienen trabajando en torno al uso del agua en las Sierras Chicas de Córdoba. Si bien analizamos la lucha de la mayoría de las organizaciones, en este caso particular nos centramos en la lucha que viene sosteniendo el colectivo Mesa del Agua y Ambiente de la localidad de La Granja, asociación que está incluida en la Coordinadora Ambiental y de Derechos Humanos de Sierras Chicas, que es la organización de organizaciones de mayor escala y representatividad a nivel regional. Nuestros aportes y reflexiones son producto del trabajo en equipos de investigación en los que venimos participando desde el año 2008 en torno a las problemáticas ambientales ${ }^{2}$.

El abordaje metodológico se realiza desde un enfoque cualitativo, con interpretación de diferentes fuentes documentales y utilizando el método etnográfico; en este sentido, se realizan entrevistas semiestructuradas a agentes claves en

\footnotetext{
${ }^{1}$ El artículo es producto de un proyecto de investigación sobre Geografía del Agua, que se desarrolla con subsidio de la Secretaría de Ciencia y Técnica (SECYT) de la UNC desde el año 2008, siendo investigador principal del mismo el profesor Sergio Chiavassa.

2 Proyectos bianuales referidos a las problemáticas del agua en la vertiente oriental de las Sierras Chicas de Córdoba, subsidiados por la Secretaría de Ciencia y Técnica de la UNC. Director del proyecto: Sergio Chiavassa.
}

el área de estudio y observación participante ${ }^{3}$, con el objetivo de visualizar, de "hacer emerger" los discursos, representaciones, visiones, imágenes, conocimientos, prácticas y posicionamientos que los distintos agentes poseen en relación a las "vivencias" referidas al agua en el área. Lo anterior supone la utilización de un enfoque metodológico orientado hacia la perspectiva del actor ${ }^{4}$. En un nivel más general, esto implica que las estructuras pueden ser modificadas desde la acción política de los propios agentes, es decir, que cualquier política - medida que se implemente en relación con la problemática, necesariamente será mediada y transformada por los actores que ya están ahí y que tienen trayectorias y prácticas ya establecidas ${ }^{5}$.

El artículo comienza con una descripción sobre el escenario del conflicto. En base a ello, se presenta la opción teórica para el abordaje de las cuencas y microcuencas del área de estudio, esto es, la importancia de considerar a la cuenca como territorio. Esto se plantea tímidamente, como para abrir el debate a la consideración del agua como bien común de la naturaleza, superadora de la noción de agua como recurso hídrico. Seguidamente entramos de lleno en el análisis de las acciones colectivas de las organizaciones sociales de Sierras Chicas, haciendo foco en la Iucha política de la Mesa del Agua y Ambiente de La Granja. En el cierre, abogamos por nuevas maneras de construir democráticamente un ambiente más sano para las poblaciones $y$, en tal sentido, proponemos avanzar en la reflexión y concreción del pos desarrollo como alternativa de futuro en la relación ambiente-sociedad.

Cabe destacar que nuestros aportes se encuentran articulados con los proyectos de investigación en los que participamos, al igual que con nuestra participación en espacios de las organizaciones involucradas.

\section{El ESCENARIO DEL CONFLICTO POR EL AGUA}

Las cuencas de Sierras Chicas presentan una superficie de captación relativamente pequeña y tienen limitada capacidad de retención lo que ocasiona, de manera cíclica, una baja disponibilidad de agua a la vez que en periodos más lluviosos, desbordes e inundaciones. En los últimos años, se han producido incendios devastadores de

\footnotetext{
3 Guber, 1991 y 2001

4 Guber, 2001 y 2011. Taylor y Bogdan, 1996.

${ }^{5}$ Bourdieu, 1991.
} 
pastizales y bosque serrano, sequías prolongadas e inundaciones catastróficas en el mes de febrero de 2015, 2016 y en las últimas seis temporadas estivales. Se trata de un territorio complejo y cambiante, que vincula espacios rurales, urbanos y rururbanos (mapa 1 ).

Los problemas ambientales de la región se ven agravados por una serie de problemáticas que afectan la natural recarga de las cuencas, como son los recurrentes incendios, la creciente ocupación de espacios con urbanizaciones de distintos niveles (planes de vivienda, loteos abiertos, barrios cerrados, complejos turísticos), la deforestación y las explotaciones dedicadas a actividades extractivas. Estos factores, al limitar la capacidad de almacenamiento del agua y su liberación gradual, introducen cambios que implican la aceleración en el escurrimiento de las aguas superficiales de origen pluvial y producen la alternancia de periodos con escasez de agua y otros con exceso.

Íntimamente relacionado con la ubicación y disposición del agua, el crecimiento poblacional de la Vertiente Oriental de las Sierras Chicas ha sido el proceso social que más ha generado el desmonte y la impermeabilización del suelo (mapa 2).

Décadas de cuencas incendiadas y desmontadas para el avance minero y urbanístico, modificaron el paisaje serrano natural y contribuyeron a la baja

Mapa 1. Cuencas de la Vertiente Oriental de las Sierras Chicas. Provincia de Córdoba, Argentina

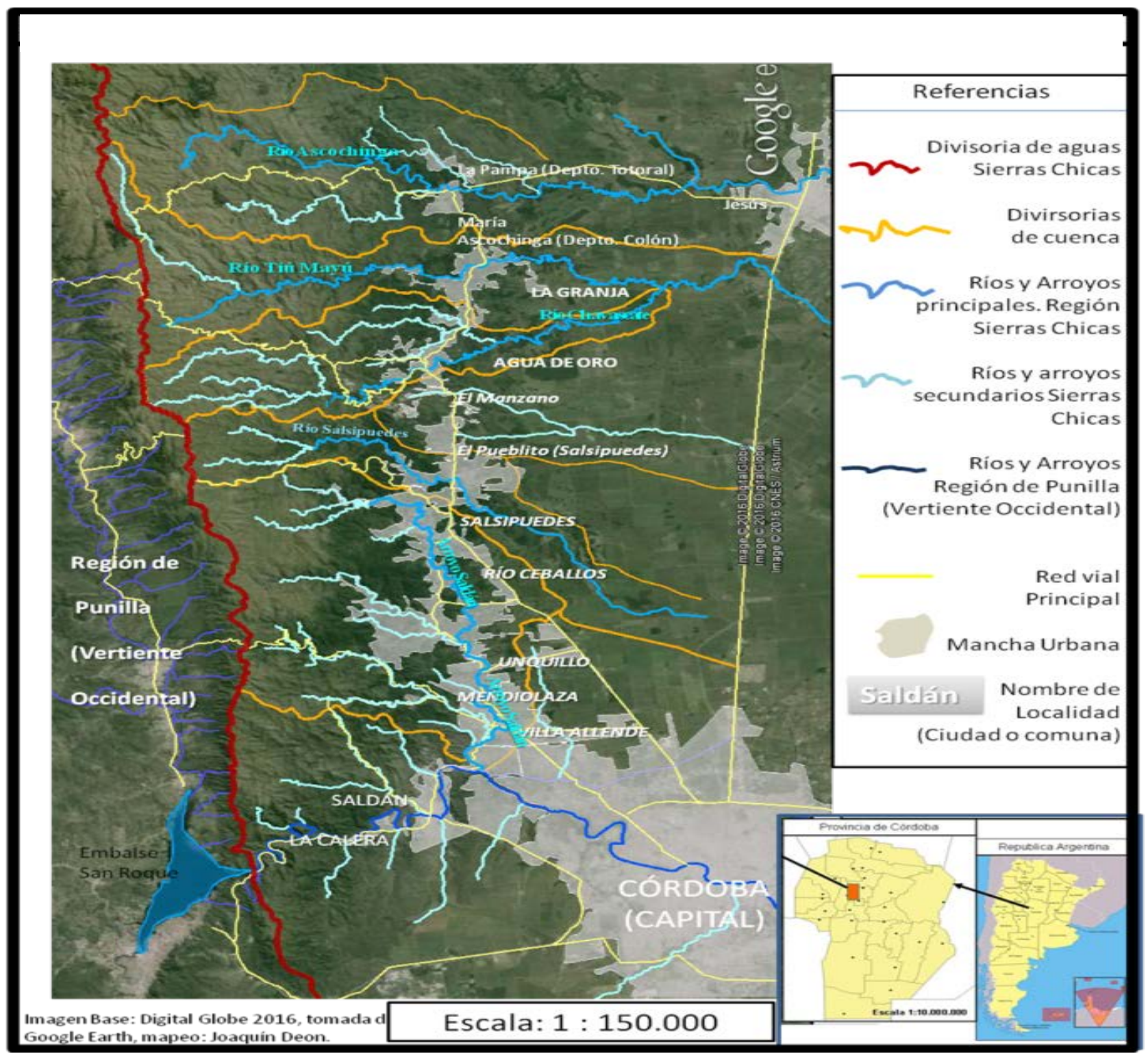


disponibilidad de agua ${ }^{6}$ en el suelo y en las tomas de captación de las localidades que se abastecen y abastecían del agua del subsuelo y arroyos serranos.
Allí se ponen en juego la multiplicidad de dimensiones que abarca el tema del agua, que, por lo evidente, supera la noción de cuenca fluvial con sus tradicionales características biofísicas

Mapa 2. Evolución del uso del suelo en las Sierras Chicas $^{7}$

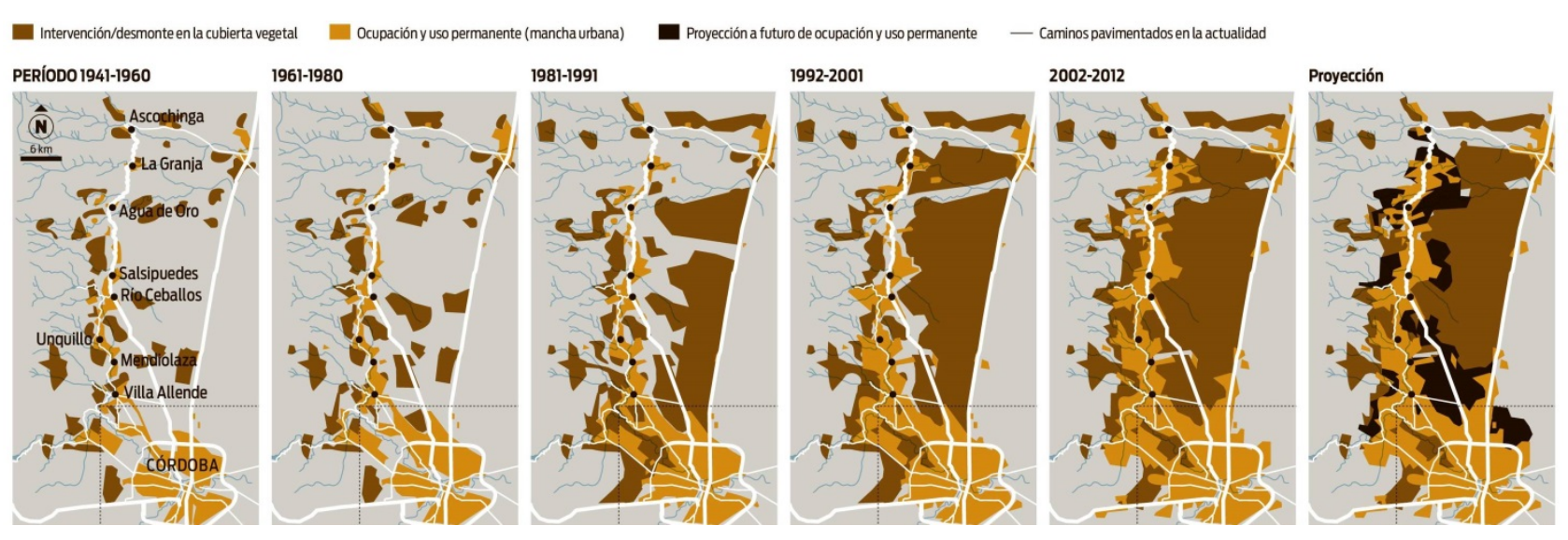

Fuente: Deón, 2014

Un "Comunicado" de la Coordinadora Ambiental y de Derechos Humanos de Sierras Chicas, fechado el 17 de febrero de 2015, da cuenta del fenómeno de las inundaciones:

“(...) más allá de la cantidad de agua caída, la 'catástrofe' no es 'natural': Lo natural es que cuando llueve el agua se infiltre y vuelva lentamente a la superficie (efecto de esponja). Pero las cuencas altas están siendo desmontadas, incendiadas y edificadas, desprotegiendo e impermeabilizando el suelo que pierde su capacidad de esponja. Ya no retiene el agua cuando llueve y no la libera cuando falta. Y así hoy, esta escurre imparable cuesta abajo (...) Lo 'natural' no es la catástrofe, lo natural son los ciclos, pero que se hacen cada vez más extremos mientras más deterioramos nuestras cuencas, que son las que los amortiguan. Lo natural es que en época de sequía las sierras entreguen el agua que acumularon en época de lluvia. Y solo recuperando ese buen estado de salud podremos recuperar el equilibrio entre que hoy sobre en demasía y mañana nos sea tan escasa. Por eso decimos que la crisis hídrica y las inundaciones son las dos caras de la misma moneda".

Así, con un discurso sencillo y una narrativa simple pero contundente, la Coordinadora -como se la conoce- dio su explicación a las inundaciones del mes de febrero de 2015.

\footnotetext{
${ }^{6}$ Chiavassa y otros, 2009, 2012 y 2013.

7 Puede verse cómo evolucionó la urbanización en el corredor Noroeste de la Gran Córdoba, abarcando las localidades del
}

(geológicas, geomorfológicas, hidrológicas) y abarca los modos de apropiación de los cursos fluviales y el uso del agua por los pobladores. Incluye también las luchas y disputas por el agua y las acciones políticas motorizadas para su defensa. Entonces, para comprender este entramado de cuestiones y visiones a distintas escalas sobre las cuencas hídricas, se trabaja las cuencas y microcuencas de la zona de estudio como territorios donde se espacializan prácticas de agentes concretos.

\section{LA CUENCA HÍDRICA COMO TERRITORIO}

Para comprender los argumentos que nos llevan a optar por el enfoque territorial en el análisis de los problemas del agua de las Sierras Chicas, comencemos por analizar qué entendemos por territorio en el sentido transformador que le atribuía Soja cuando expresaba: "nosotros hemos producido nuestros espacios y podemos cambiarlos" 8 .

Para ello partimos de las dimensiones espacial y temporal de la vida social. Y esto nos invita a superar la imagen del espacio como un continente o receptáculo y entender la espacialidad como una compleja dimensión de la vida social ${ }^{9}$. Estamos acostumbrados a mirar el territorio como

\footnotetext{
faldeo oriental de las Sierras Chicas

8 Soja, 2004.

${ }^{9}$ Piazzini, 2006. Soja, 1993 y 2004.
} 
un background, algo fijo, muerto, natural, que está allí afuera, contenedor. Pero, como decía Soja, ahora estamos tratando de pensar en un modo más dinámico sobre territorio y políticas y sobre territorio y sociedad, y esta es la perspectiva real ${ }^{10}$. Entonces se trata de alentar un modo de mirar el mundo que se focaliza en la práctica, en esta noción de desarrollo espacial como una fuerza integrada.

Es que comprender la espacialidad de las prácticas sociales, es una tarea muchas veces pendiente para las ciencias sociales. En la construcción del territorio hay un encuentro de distintas temporalidades que están presentes y "coexisten en el espacio"11 o "el espacio es acumulación desigual de tiempos" ${ }^{12}$, es "el locus donde diferentes temporalidades conviven" ${ }^{13}$.

Siguiendo la línea argumental de Porto Gonçalves (2012), "el territorio es una categoría espesa" que presupone un espacio geográfico que es apropiado y ese proceso de apropiación -territorialización- encierra, incluye, conlleva identidades -territorialidades- que están inscriptas en un proceso y, por tanto, son dinámicas y mutables, materializando en cada momento un determinado orden, una determinada configuración territorial. En este sentido, estamos lejos de un espacio-sustancia y delante de una tríada relacional territorio-territorialidadterritorialización. "La sociedad se territorializa siendo el territorio su condición de existencia material"14. Es preciso considerar aquí que la geograficidad va más allá de las condiciones naturales. Por supuesto que la naturaleza es parte de la materialidad que constituye el espacio geográfico, pero este es al mismo tiempo material y simbólico.

Para Raffestin, existe una diferencia entre el espacio "realidad material preexistente" y el territorio, que es producto de una acción social. Al apropiarse del espacio, concreta 0 abstractamente, el sujeto social territorializa el espacio. Al territorializar, él entra en un campo de poder que no es apenas la apropiación física, material (por medio de fronteras jurídicopolíticas), sino también inmaterial o simbólica, ya que las representaciones sobre el territorio son, además, instrumentos de poder ${ }^{15}$.

Al incorporar la noción de territorio se refuerza la dimensión de apropiación y control de una porción del espacio por parte de agentes particulares, con posiciones diferenciadas en las relaciones de poder. Esta apropiación o control comprende no solo la dimensión material del espacio sino también la dimensión política (que involucra al tiempo que excede lo meramente institucional) y la simbólica-cultural ${ }^{16}$. Para este último, la territorialización significa crear mediaciones espaciales que nos proporcionan un efectivo poder sobre nuestra reproducción en cuanto grupos sociales (para algunos también en cuanto individuos), "poder que es siempre multiescalar y multidimensional, material e inmaterial, de 'dominación' y 'apropiación' al mismo tiempo" ${ }^{17}$.

Así, el espacio geográfico "es una condición para la acción; una invitación a la acción" ${ }^{18}$. De este modo, considerar la geograficidad es hacer como que la historia se reconcilie con la vida en la materialidad de la relación sociedad-naturaleza. Y así llegamos y le encontramos sentido a la inclusión de la lucha política en el territorio, aspecto sobre el que volvemos más adelante.

Si consideramos que el espacio no constituye una estructura autónoma e independiente con sus propias reglas de construcción y transformación, sino que representa una definida dimensión de la vida social $y$, por tanto, en ese espacio se establecen relaciones de poder que atraviesan las dimensiones políticas, socioeconómicas y culturales, se configura un territorio. Como lo expresa Lopes de Souza: "El espacio determinado y delimitado por y a partir de relaciones de poder, definiendo un límite y operando sobre un sustrato referencial" 19 constituye lo que entendemos como territorio.

Por eso sostenemos que el agua tiene que ser pensada en cuanto territorio, esto es "en cuanto inscripción de la sociedad en la naturaleza, con todas sus contradicciones implicadas en el proceso de apropiación de la naturaleza por mujeres y

\footnotetext{
${ }^{10}$ Soja, 2004.

${ }^{11}$ Harvey, 1998.

12 Santos, 1996.

13 Porto Gonçalves, 2014.

14 Porto Gonçalves, 2002.
}

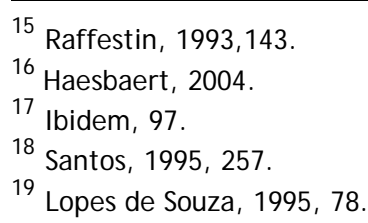


hombres por medio de las relaciones sociales y de poder" ${ }^{20}$.

El territorio se conforma entonces en zona de disputa donde los distintos agentes que actúan en él, intentan imponer sus condiciones de poder y sus lógicas de acción guiadas, al decir de Leff, por racionalidades específicas ${ }^{21}$. Estas prácticas sociales afectan no solo a los demás agentes insertos en el espacio, sino al espacio mismo. De esta manera, se producen transformaciones, que asociadas a problemáticas ambientales, plantean conflictos y ponen de manifiesto las tensiones que sufre el territorio.

En este sentido, los conflictos muchas veces aparecen como respuestas puntuales a hechos locales. De allí que la primera reacción es a nivel local, sin advertir que el problema es territorial, en el sentido de territorio que aquí tratamos; un espacio mucho mayor que inclusive, tomando por caso el agua, supera el área de la cuenca hidrográfica donde está asentado el conflicto y generalmente abarca varios pueblos que pertenecen a administraciones políticas diversas, a la vez que las cuencas están incluidas en este caso en una determinada jurisdicción provincial que pertenece a un Estado nacional. Estos niveles jurídico-políticos también entran en la arena de disputa por el agua y los usos del suelo ${ }^{22}$.

En síntesis, tomar a la cuenca como territorio, es abarcar un espacio que ya no solo se define en su dimensión biofísica y ecológica, sino que contiene dimensiones sociales y políticas, que hacen necesario un enfoque territorial en la búsqueda de soluciones ${ }^{23}$.

Metodológicamente, abordamos estas cuestiones desde la perspectiva del actor, en la cual, los diversos dominios sociales se entrecruzan y son mutuamente construidos. Focalizar la atención en ese entrecruzamiento de dominios sociales o interfase de diferentes actores permite ver arenas de conflicto donde se negocian prácticas, discursos y sentidos ${ }^{24}$.

El entramado de actores que inscriben sus prácticas en el territorio, es variado y complejo. A riesgo de simplificar, podemos nombrar los vecinos que demandan y consumen, las

\footnotetext{
${ }^{20}$ Porto Gonçalves, 2004.

21 Leff, 2001.

22 Para profundizar en el caso argentino, se recomienda consultar a Carrizo y Berger, 2013.

${ }^{23}$ Castro, 2014.

${ }^{24}$ Rodríguez Bilella, 2008.
}

Cooperativas que abastecen de agua y de otros servicios básicos a las comunidades. Están también las comunas y municipios, es decir los gobiernos locales que enfrentan año tras año, en épocas de sequías severas, los reclamos de los vecinos porque se quedan literalmente sin agua.

El trabajo etnográfico nos ha permitido visualizar tensiones entre actores nuevos y ya establecidos. Se afectan las relaciones preexistentes, aquellas que dieron forma al territorio actual y entran en discusión al momento de dar cuenta de su posición ante el problema. Ejemplo de esto son los conflictos que se establecen entre habitantes de la cuenca baja y la cuenca alta, donde los primeros aducen que el incorrecto uso del espacio a través de una producción ineficiente y excesiva, desmonte y uso del fuego como práctica cultural, afecta la disponibilidad de agua en la cuenca baja. Mientras que los habitantes de la cuenca alta exteriorizan que el aumento desmedido y sin planificación de la urbanización en la zona baja, pone en riesgo sus formas de vida y producción. Esto se vuelve más complejo por la presencia de nuevas urbanizaciones en la zona alta de las cuencas, generándose conflictos entre actores internos y externos a las mismas. Se aprecian diferencias entre los agentes que ostentan capacidad y poder económico, como los desarrolladores inmobiliarios y urbanísticos que perciben al territorio como una oportunidad económica, donde el agua es un factor más de la ecuación costo beneficio, y gran parte de la comunidad que asume al agua en su dimensión social.

Por lo dicho hasta aquí, lo que marca un proceso de conflicto territorial por el agua y el uso del suelo es la materialización de la lucha en posturas que permiten pensar la complejidad del espacio en que se habita y produce, es decir, la cuenca ${ }^{25}$.

\section{El AGUA: DE RECURSO A BIEN NATURAL}

Otra categoría clave sobre la que queremos avanzar en esta línea de trabajo que articula lo ambiental con los movimientos sociales, es considerar el "bien común" o los "bienes comunes de la Naturaleza", incluida el agua, y dejar de considerarla como un "recurso natural".

Es en esta dirección que las organizaciones sociales de Sierras Chicas avanzan. Impulsan

\footnotetext{
${ }^{25}$ Deón, 2015.
} 
acciones que garanticen el derecho de acceso al agua a toda persona que habita ese territorio, pensando el agua como un elemento vital y no como un elemento de consumo atado a prácticas mercantilistas y/o a usos suntuosos. "En tanto podemos pensar al agua como un bien o una mercancía, también debemos hacerlo principalmente como un elemento vital; con un solo valor asignable: el de la vida misma" ${ }^{26}$.

Las problemáticas derivadas del proceso histórico de apropiación de los componentes de la naturaleza, han derivado en una crisis ambiental global, que moviliza a intelectuales, organizaciones sociales y poblaciones en distintas latitudes del planeta. En el marco del Estado, la lógica del mercado invadió todos los sectores de la vida, exacerbando el individualismo. Se estableció como imperativo ético la concepción del progreso indefinido de la humanidad, sustentado en la concepción de un planeta inagotable y capaz de resolver las contradicciones por la ciencia y la tecnología. El paradigma de la modernidad desembocó en la sobre-explotación de la naturaleza, es decir, en la devastación de la fuente de la vida (la madre-tierra). El cuestionamiento de fondo es ¿qué valor asignamos al ambiente, a la naturaleza y sus elementos, al entorno?

Para Eduardo Gudynas el antropocentrismo prevaleciente en el actual modelo de desarrollo, lleva a controlar y manipular la naturaleza con el objetivo casi único de asegurar el crecimiento económico. Propone, entonces, romper con el antropocentrismo, defendiendo la existencia de valores propios en los seres vivos y en el ambiente ${ }^{27}$. Estos son valores independientes de los intereses y utilidades del hombre, son propios de la naturaleza, son intrínsecos e inherentes a los seres vivos y sus ambientes y, por lo tanto, son independientes de las valoraciones que se hacen basadas en la utilidad comercial de los recursos naturales.

Por su parte, François Houtart, preocupado por el agotamiento de los recursos naturales, propone "revisar la orientación de base del vivir colectivo de la humanidad" y elaborar una nueva

\footnotetext{
26 Idem.

27 Apoya posturas biocéntricas donde la Naturaleza ocupa un lugar central, la cultura y las sociedades humanas se insertan dentro de la Naturaleza (postura de muchos pueblos indígenas, Gudynas, 2015, 62). La Naturaleza separada de la sociedad y dividida en elementos que pueden ser estudiados, dominados, explotados y controlados, es la herencia de la colonialidad europea (Ibidem, 134).
}

episteme que incluye, entre otros fundamentos, una nueva relación con la naturaleza y una renovación en la producción de la base material de la vida, física, cultural y espiritual:

"Se trata de vivir bien, de cumplir con el Bien Común de la Humanidad, lo que implica, como primer paso, el respeto de la integridad de la naturaleza, como fuente de vida (la madre-tierra). Su construcción y sus aplicaciones en los fundamentos de la vida colectiva en el planeta, es un proceso. No es solamente de un ejercicio académico, sino (de) una elaboración social, donde el pensamiento tiene un lugar esencial, pero también la experiencia concreta, en particular las luchas sociales, que corresponden cada una a una falla de cumplimiento del Bien Común de la Humanidad y que buscan soluciones" 28 .

Una nueva concepción de las relaciones con la naturaleza conlleva no aceptar la propiedad privada de los recursos naturales, es decir de los minerales, las energías fósiles, las selvas. Se trata de un patrimonio común de la humanidad que no puede ser apropiado por individuos y corporaciones, siguiendo la lógica de la economía de mercado capitalista, es decir en función de intereses privados.

Otro aspecto es el rechazo a la mercantilización de los elementos necesarios para la reproducción de la vida, como el agua y las semillas. Son bienes comunes que deben salir de la lógica de la mercancía y entrar en una perspectiva de gestión común según varias modalidades, que no implican necesariamente la estatización sino el control colectivo.

Privilegiar el valor de uso sobre el valor de cambio significa también redescubrir el territorio. El territorio como espacio de actividad económica, pero también de responsabilidad política y de intercambio cultural donde es posible construir otra racionalidad ambiental.

En esta nueva episteme, adquieren protagonismo las acciones colectivas, y el caso de la región de Sierras Chicas no es la excepción. Volviendo a los postulados de Soja, lo que está ocurriendo es la aparición de nuevas clases de movimientos territoriales, movimientos socioespaciales o movimientos sociales territorializados, que están empezando a ver la necesidad de cambiar desde un pensamiento histórico hacia un nuevo pensamiento territorial, donde lo territorial en la escala local está virando hacia lo social, lo

\footnotetext{
${ }^{28}$ Houtart, 2011, 21.
} 
político, lo económico, lo cultural y, de alguna manera, desarrollando un nuevo nivel de pensamiento que realmente no existía con anterioridad $^{29}$.

\section{LAS ORGANIZACIONES SOCIALES DE SIERRAS ChICAS}

Varios pensadores latinoamericanos que transitan el continente hacen emerger las voces de los que luchan desde abajo por sus territorios. Nos referimos entre otros a Arturo Escobar, Eduardo Gudynas o Carlos Porto Gonçalves ${ }^{30}$, por solo nombrar algunos que, desde posturas decoloniales, defienden los derechos de la naturaleza y apoyan estas luchas que, además de ser ambientales, son ante todo, luchas antisistémicas que brotan desde abajo por las injusticias que ha provocado el sistema de explotación colonial/ europeo.

La multiplicidad de crisis que se agudizaron en los últimos tiempos, son el resultado de la misma lógica de fondo: (1) una concepción del desarrollo ignorando las externalidades (es decir los daños naturales y sociales); (2) la idea de un planeta inagotable; (3) la prioridad dada al valor de cambio sobre el valor de uso y (4) la identificación de la economía con la tasa de ganancia y la acumulación del capital que crea, consiguientemente, enormes desigualdades económicas y sociales. Acá rescatamos las palabras de Porto Gonzalves para quien las luchas extremadamente importantes en nuestra América latina, son las luchas territoriales. En este sentido, para el autor dentro de un territorio nacional existen múltiples territorialidades; el concepto de territorio fue desnaturalizado en el momento mismo de la conquista y colonización y, sobre todo, en la conformación de los estados nacionales. Fue un proceso de disputa por el control del espacio y fue un proceso de despojo para cientos y miles de pueblos, de etnias, de religiones, de lenguas, de naturaleza, de riquezas, de vida. Dentro de nuestros territorios hay conflictos intensos y son los movimientos sociales de lucha y de resistencia, los que nos obligan a poner en cuestión, en un intenso debate, la

\footnotetext{
${ }^{29}$ Soja, 2004.

30 Varios pensadores provenientes de distintas formaciones académicas, enmarcados en esta nueva episteme, han formado el grupo Modernidad/Colonialidad, que viene publicando desde 2005 la revista Tábula Rasa, desde la que difunden su pensamiento. Para ampliar estos temas, se puede consultar, Alimonda, 2002 y 2011; Escobar, 2005; Acosta y Martínez, 2014, y Lang y Mokrani, 2011.
}

relación de los pueblos con la Naturaleza, con los territorios de vida, a la par que debemos también cuestionar el modelo de desarrollo imperante. J ustamente son estos movimientos de lucha los que nos proponen pensar otras alternativas al desarrollo ${ }^{31}$. Este modelo que dio lugar a un desarrollo espectacular de la riqueza mundial, ha llegado al fin de su función histórica por su carácter destructor de la naturaleza y por la desigualdad social que ha provocado.

Volviendo al caso que nos ocupa, el problema del agua en las Sierras Chicas ha motorizado a grupos de vecinos desde 2007 y con diversos grados de organización, están llevando adelante importantes reclamos en defensa del agua, por la accesibilidad y calidad y por los usos del suelo y de los bosques. En definitiva, están poniendo en tensión las formas de apropiación, producción, distribución y gestión de los recursos naturales en cada comunidad y a nivel regional.

En efecto, los colectivos de Sierras Chicas, luchan por mejores condiciones de vida, exigiendo mayor participación en las políticas públicas, desde y en sus territorios. Se colocan así en la misma línea de los múltiples reclamos que existen en diversas localidades de nuestra América. $Y$ es significativo considerar que el anclaje territorial de las organizaciones sociales tiene mucha importancia para la ampliación democrática de nuestras sociedades. En este sentido, en torno al agua se están construyendo nuevos espacios públicos en el nivel microlocal a partir de las prácticas de las organizaciones comunitarias. El análisis de organizaciones como los Consejos Comunales y las Mesas del Agua, muestra logros, dificultades y contradicciones en los que están insertas sus prácticas comunitarias.

En Ias Sierras Chicas, organizaciones sociales, instituciones intermedias (como cooperativas) y algunas dependencias públicas municipales se han unido y organizado en la Coordinadora Ambiental y de Derechos Humanos de las Sierras Chicas ${ }^{32}$ y desde el 2012 trabajan para establecer acciones comunes tendentes a un trabajo en red, "como

\footnotetext{
31 Porto Gonçalves, 2014.

32 Grupo EsCalera (La Calera), Fundación Vertientes de Saldán (Saldán), Grupo Tacku (Villa Allende), Guardianes del Monte (Mendiolaza), Vecinos Autoconvocados (Unquillo), Asociación Civil Los Manantiales (Río Ceballos), CoVeSa (Salsipuedes), Fundación Eco-Barrio San Miguel (Salsipuedes), Coop. de Agua (Agua de Oro), Vecinos del Chavascate en Defensa del Agua, el Ambiente y la Calidad de Vida (Agua de Oro, Villa Cerro Azul), Colectivo Sin Frenos (Villa AniMi), Mesa del Agua de la Granja, Comunidad ContrArte, Grupo Coyuyo.
} 
deseo de implementar acciones conjuntas que permitan defender el ambiente de cada comunidad trabajando mancomunadamente las problemáticas ambientales de las Sierras Chicas en pos del desarrollo sustentable" ${ }^{33}$. Intentan otorgarle un sentido al ambiente, rescatando sus valores sociales como prestador de servicios ambientales; se trata de una lucha, en común, por los derechos sobre el agua, la tierra, el bosque y la identidad local.

La Coordinadora realiza una vez al año la "Cruzada de las Sierras Chicas por la soberanía del agua y la tierra" ${ }^{34}$. El trabajo sobre las reservas hídricas, por ejemplo, es una clara demostración de que es posible generar una serie de áreas naturales protegidas que, superando los límites político-administrativos de los municipios, permita crear un comité de cuencas de las Sierras Chicas que otorgue seguridad al bosque y proteja las cuencas altas de los ríos y arroyos ante el avance de la urbanización, los incendios, el desmonte para la ganadería y los proyectos de trasvase de cuenca.

Esta lucha en defensa de la tierra, el agua y el bosque, no solo se presenta a escala local como ya fue dicho. A nivel regional se están dando sucesivas movilizaciones en localidades como Mendiolaza en torno al desmonte para la urbanización denominada "El Terrón", en Villa Allende respecto de la Reserva Hídrica Recreativa y Natural Villa Allende, en La Granja respecto del acueducto Tiu Mayú-La Cumbre, en La Calera respecto de la "Reserva Bamba" ${ }^{35}$, en Saldán por la "Reserva Hídrica Saldán Inchín", por nombrar algunas...

Luchas emblemáticas a nivel nacional, como la resistencia a la minería a cielo abierto, las movilizaciones y debates en torno a la sanción de la ley de protección de bosques nativos o la ley de

\footnotetext{
33 Eckstein, 2012.

34 El objetivo central de las sucesivas Cruzadas consiste en dar visibilidad a los conflictos en torno al agua y la tierra que ocurren en cada uno de los territorios en particular y en toda la región en general, a través de una acción concreta colectiva: una caminata de tres días, pasando una bandera como posta simbólica de lucha colectiva. En cada localidad, además, se llevan a cabo intervenciones culturales, artísticas, musicales, mesas y charlas informativas, talleres, etc.

35 La Reserva Natural de la Defensa, "La Calera", fue declarada en 2010 en los campos militares del Tercer Cuerpo de Ejército, gracias a la iniciativa del Grupo Escalera y el Aula Abierta de Montaña, dos colectivos que lucharon incansablemente para hacer realidad este objetivo. Palacio et al, 2010, y Eckstein, 2012.
}

glaciares, la oposición a nuevas instalaciones de rellenos sanitarios en la metrópoli de Buenos Aires, las demandas de los vecinos afectados por la contaminación con agroquímicos (los "pueblos fumigados") son la cara más visible de otras tantas manifestaciones que expresan una creciente conflictividad en relación al acceso, la disponibilidad, la apropiación, la distribución y la gestión de los recursos naturales. Estas expresiones, que han ganado la calle y se manifiestan en el espacio público, abren debates en torno a los supuestos beneficios del desarrollo en términos de impacto ambiental en el mediano y largo plazo y de afectación al territorio ${ }^{36}$.

Se trata de organizaciones socioterritoriales ambientalistas, cuyo accionar se carga de sentido más allá de los límites políticos de cada jurisdicción. Las movilizaciones de estos pueblos "crean sentido al borde del abismo" ${ }^{37}$, es decir que se trata de una frontera social, que nos permite hablar de "esta" sociedad y no de otra y es una frontera cargada de significados. Así, se rompe con la noción territorial asociada a lo políticoadministrativo, es decir, a lo estatal-nacional. Las organizaciones manifiestan discursivamente su frontera de sentido en torno a la cuenca del río, como espacio donde converge y se genera el agua y donde se encuentra el ambiente con el que se identifican. Esto se contrapone a la delimitación llevada a cabo por los municipios y comunas, en tantas unidades territoriales administrativas, pues se circunscriben meramente al territorio en el cual prestan servicios, cobran impuestos o encuentran a sus votantes a la hora de las elecciones ${ }^{38}$.

Con esto podemos decir que la dificultad empírica de establecer fronteras de sentido en torno a los colectivos sociales ${ }^{39}$, es también reductible a los espacios regionales debido a que en ellos podemos encontrar intereses contrapuestos y concepciones diversas en torno al territorio. El discurso y la lucha de los "ambientalistas" 0 "conservacionistas" no es igual al interés de los inversionistas y su visión de la serranía cordobesa urbanizada o "dinamitada" (para el caso de la minería a cielo abierto no metalífera), o de los vecinos más tradicionalistas que prefieren no involucrarse en procesos sociales tendientes a la conservación de espacios desde los cuales también

\footnotetext{
36 Merlinsky, 2013, 40.

${ }^{37}$ Castoriadis, 2004.

38 Deón, 2015.

${ }^{39}$ Castoriadis, 2004.
} 
ellos reciben el agua que beben o el aire puro que respiran.

Esta es la alternativa que encuentran los grupos movilizados a nivel local, la misma que los lleva a unirse a otras escalas y, de esta manera, generar espacios de participación ciudadana y solidaridad colectiva, espacios no construidos como copias de otras experiencias, sino como construcciones sociales acordes a cada territorio y sociedad movilizada en el mismo. En este marco es fundamental destacar y dar a conocer las acciones de las diversas organizaciones sociales e instituciones de la sociedad de este sector de la provincia de Córdoba en torno a la protección de derechos ciudadanos y su articulación con otras organizaciones (tabla 1).

\section{LA LUCHA POLÍTICA DE LA MESA DEL AGUA Y AMBIENTE (MAYA) DE LA GRANJ A}

Dentro de las organizaciones sociales que presentamos en el cuadro precedente, el proceso de acción política desarrollado por la MAYA de La Granja, resulta interesante.

¿Cómo surge la MAYA? En 2008 se constituyó el primer equipo de investigación avalado por la SECYT sobre "Geografía del agua. El caso de la vertiente oriental de las Sierras Chicas". Su objetivo central era "analizar las problemáticas que se vinculan a la disminución en la oferta de agua, así como los conflictos que se manifiestan por intereses muchas veces contrapuestos entre los diferentes agentes sociales y actividades que coexisten en el área de estudio" ${ }^{40}$. Desde el equipo de docentes se realizaron las tareas de campo, se comenzó a producir y a propiciar contactos con la gente del lugar y con instituciones relacionadas a la temática. Este trabajo territorial desembocó en acciones concretas, como la creación de "La Mesa del Agua y Ambiente" formada por vecinos junto a miembros de la Municipalidad de La Granja ${ }^{41}$, a fines del año 2011.

La lucha estuvo orientada desde los inicios, a mejorar el manejo en la distribución, acceso y calidad del agua potable. Asimismo, se

\footnotetext{
40 Proyecto de investigación, SECYT/UNC. Director: Sergio Chiavassa.

${ }^{41}$ La localidad de La Granja se encuentra ubicada en el departamento Colón de la provincia de Córdoba. Las crisis hídricas se relacionan con el crecimiento demográfico-urbano que ha tenido la localidad en los últimos años, pasando de 1.936 habitantes en 2001 a 2.456 en el censo de 2010 .
}

presentaron proyectos enfocados a la atención del arroyo, el cauce, las orillas, el paisaje circundante, las edificaciones... Paralelamente, se comenzó a trabajar en defensa de otros componentes del ambiente, principalmente la preservación del monte, la prevención de incendios forestales, de los suelos, de las laderas serranas. Desde su origen, el colectivo comienza a interactuar con la ya mencionada "Coordinadora Ambiental y de Derechos Humanos de Sas Chicas".

El colectivo MAYA plantea demandas y reclamos ambientales a través de lo que ellos denominan asociación de autoconvocados.

Entre los reclamos, podemos escuchar lo siguiente:

"tenemos un problema con la localidad de La Cumbre. Entre los dos pueblos hay un paraje Ilamado Asno Rodeo en el cual estaban haciendo un country de altura y pretendían tirar los efluentes hacia la localidad de La Granja, lo que iba a llevar a una inminente contaminación de las vertientes naturales que se encuentran en dicha localidad, y gracias a la lucha de los vecinos esta obra no se concluyó" ${ }^{42}$.

Al decir de Merlinsky ${ }^{43}$ "en un formato organizativo de gran flexibilidad, la acción colectiva requiere de una activación permanente de las relaciones entre los participantes, quienes se comunican y adoptan decisiones a partir de los acontecimientos que se suceden en el espacio público".

Otro de los argumentos esgrimidos es el del Plan de Ordenamiento Urbano ${ }^{44}$, sienten que no los representa y que es necesario hacer una revisión del mismo con la más amplia participación de los vecinos. Al respecto, expresan lo siguiente:

"han puesto franjas de color verde para hacer barrios cerrados en los predios de la Fuerza Aérea, cuando a esos predios se los iban a declarar como reserva" 45 .

Sucesivas reuniones permitieron enriquecernos mutuamente y valernos del formato asambleario de la MAYA para impulsar deliberaciones grupales sobre diferentes tópicos que ampliaran la exploración de argumentos, tanto para los

\footnotetext{
42 Julio, integrante de la MAYA. La Granja, agosto de 2014.

43 Merlinsky, 2013.

44 En 2007 se elaboró por iniciativa privada, y con subsidio de la UNC, un Plan de Ordenamiento Urbano (POU) para la localidad de La Granja que fue presentado a la Municipalidad. En ese entonces, los vecinos no habían sufrido ni las crisis hídricas, ni las inundaciones, con lo cual el Plan quedaba desactualizado.

45 Francisco, integrante de la MAYA. La Granja, agosto de 2014.
} 
Territorialidades en conflicto y acciones colectivas: las luchas por el agua en Sierras Chicas, provincia de Córdoba, Argentina

Tabla 1. Organizaciones sociales e instituciones de las Sierras Chicas

\begin{tabular}{|c|c|c|c|}
\hline Localidad & $\begin{array}{l}\text { Organización } \\
\text { social o } \\
\text { institución }\end{array}$ & Actividades que desarrolla & Problemáticas que identifica a escala local o regional \\
\hline La Granja & $\begin{array}{c}\text { Mesa del Agua y } \\
\text { Ambiente de La } \\
\text { Granja }\end{array}$ & $\begin{array}{l}\text { Talleres, charlas y elaboración de proyectos para la } \\
\text { conservación de la cuenca de los ríos San Miguel y Tiú } \\
\text { Mayú y en defensa del bosque nativo. } \\
\text { Proposición de nuevo plan de ordenamiento urbano. }\end{array}$ & $\begin{array}{l}\text { Inadecuado tratamiento de RSU. Urbanización } \\
\text { desmedida y no planificada. Falta de control en el } \\
\text { suministro de agua domiciliario. Trasvase de cuenca Tiu } \\
\text { Mayú-San Gerónimo, disminución del caudal y cantidad } \\
\text { de agua disponible en arroyo. }\end{array}$ \\
\hline $\begin{array}{l}\text { La Granja- } \\
\text { VIIla Animi }\end{array}$ & $\begin{array}{l}\text { Colectivo sin } \\
\text { frenos }\end{array}$ & $\begin{array}{l}\text { Comunicación comunitaria. Creación de espacios de } \\
\text { debate de problemática y elaboración de soluciones a } \\
\text { escala local. Ropero comunitario, Radio Abierta, Revista } \\
\text { Rebelde Amanecer y el Zumbón. } \\
\text { Realización de migas -construcciones vecinales } \\
\text { sustentables-. }\end{array}$ & $\begin{array}{l}\text { Falta de espacios públicos de discusión, debate y } \\
\text { difusión de problemáticas locales tales como: } \\
\text { desmontes, mala distribución del agua, falta de } \\
\text { información general sobre la comunidad y los proyectos } \\
\text { edilicios o urbanísticos existentes, construcción } \\
\text { sustentable. }\end{array}$ \\
\hline $\begin{array}{l}\text { Agua de Oro, } \\
\text { El Manzano y } \\
\text { Villa Cerro } \\
\text { Azul }\end{array}$ & $\begin{array}{l}\text { "Nuestra Agua" } \\
\text { Vecinos del } \\
\text { Chavascate }\end{array}$ & $\begin{array}{l}\text { Construcción del Ordenamiento Territorial Participativo } \\
\text { (O.T.P.) de la Cuenca del Río Chavascate. Jornadas de } \\
\text { limpieza del río. Realización de charlas-debate sobre la } \\
\text { situación de escasez de agua en la red de distribución de } \\
\text { agua local. Participación en el consejo directivo de la } \\
\text { Cooperativa de Agua local. Presentación de proyectos y } \\
\text { propuestas ante el Ejecutivo Municipal de las comunas de } \\
\text { Villa Cerro Azul y El Manzano y de la Municipalidad de } \\
\text { Agua de Oro y su Concejo Deliberante. }\end{array}$ & $\begin{array}{l}\text { Cumplimento de la Ordenanza que crea la Reserva } \\
\text { Hídrica de Villa Cerro Azul. La Aprobación del O.T.P en } \\
\text { la Legislatura Provincial y en el Ejecutivo Provincial, } \\
\text { como así también en las comunas de El Manzano y el } \\
\text { municipio de Agua de Oro, quienes poseen ejido } \\
\text { municipal en la cuenca del río Chavascate. No a la } \\
\text { aprobación de los loteos proyectados en la cuenca } \\
\text { media-alta del río Chavascate. }\end{array}$ \\
\hline Agua de Oro & $\begin{array}{l}\text { Cooperativa de } \\
\text { Obras y Servicios } \\
\text { Públicos Agua de } \\
\text { Oro Limitada }\end{array}$ & $\begin{array}{l}\text { Prestación del servicio de Agua Potable en las localidades } \\
\text { de Agua de Oro, El Manzano y Villa Cerro Azul. Servicio } \\
\text { de teléfono e internet en la primera. Actividades } \\
\text { educativas en torno al agua y el bosque nativo en } \\
\text { escuelas locales. Publicaciones semanales y mensuales } \\
\text { sobre el agua, servicios cooperativos y saneamiento de } \\
\text { aguas grises y cloacales. }\end{array}$ & $\begin{array}{l}\text { Evitar el deterioro y contaminación de la fuente de } \\
\text { provisión de agua de la comunidad. Conservar la cuenca } \\
\text { a través del O.T.P. Ampliar la provisión del servicio de } \\
\text { agua a toda la población de las tres localidades. Falta } \\
\text { de accionar conjunto entre el municipio y la } \\
\text { Cooperativa. }\end{array}$ \\
\hline Salsipuedes & $\begin{array}{l}\text { Asociación Civil } \\
\text { Salsiquieres } \\
\text { "Radio La Curva" } \\
\text { y CoVeSa } \\
\text { (Comisión de } \\
\text { Vecinos de } \\
\text { Salsipuedes) }\end{array}$ & $\begin{array}{l}\text { Radio La Curva (FM 99.5) transmite desde el año } 2010 \\
\text { contribuyendo a la comunicación interorganizacional y } \\
\text { vecinal sobre "Io que pasa en la zona con el agua y el } \\
\text { ambiente", arraigándose a la tierra a través del } \\
\text { acompañamiento de proyectos comunicacionales de otras } \\
\text { organizaciones o vecinos de las Sierras Chicas, como el } \\
\text { de "hierbas serranas" o "colectando agua". } \\
\text { CoVeSa desarrolla actividades en torno a la Reserva } \\
\text { Hídrica de Salsipuedes y la defensa del patrimonio } \\
\text { forestal local. }\end{array}$ & $\begin{array}{l}\text { Resaltan la importancia de comunicar qué sucede con la } \\
\text { problemática hídrica local y los trasvases de cuencas. } \\
\text { Preocupación por los incendios frecuentes en la cuenca } \\
\text { del arroyo La Estancita y Salsipuedes. }\end{array}$ \\
\hline Río Ceballos & $\begin{array}{l}\text { Asociación Civil } \\
\text { Los Manantiales }\end{array}$ & $\begin{array}{l}\text { Da a conocer, con jornadas a campo, la situación de la } \\
\text { Reserva Manantiales. } \\
\text { Promoción de la conservación de la cuenca del Arroyo } \\
\text { Mal Paso }\end{array}$ & $\begin{array}{l}\text { Falta de planificación, control y ordenamiento de la } \\
\text { vertiente oriental de la Sierras Chicas. Crecimiento } \\
\text { "desordenado" de la mancha urbana del Gran Córdoba. } \\
\text { Pérdida de monte nativo. }\end{array}$ \\
\hline Unquillo & $\begin{array}{l}\text { Asociación de } \\
\text { vecinos de } \\
\text { Unquillo por la } \\
\text { vida y el } \\
\text { ambiente }\end{array}$ & $\begin{array}{l}\text { Conservación de la cuenca del Arroyo Los Quebrachitos. } \\
\text { Conservación de la Reserva Hídrica y Recreativa, Los } \\
\text { Quebrachitos. Marchas por la relocalización de antenas } \\
\text { de telefonía celular. }\end{array}$ & $\begin{array}{l}\text { Desmontes e incendios en la cuenca del arroyo. } \\
\text { Ubicación de antenas en el centro de la ciudad. }\end{array}$ \\
\hline Mendiolaza & $\begin{array}{l}\text { Guardianes del } \\
\text { Monte }\end{array}$ & $\begin{array}{l}\text { Talleres de reconocimiento de flora y fauna en el predio } \\
\text { de El Terrón. Marchas y protestas por el no cierre y } \\
\text { urbanización de las } 280 \text { ha del predio de El Terrón. } \\
\text { Elaboración de propuestas para la prestación del servicio } \\
\text { de agua potable a Barrio El Talar. }\end{array}$ & $\begin{array}{l}\text { Ausencia de una gestión social del agua. Falta de agua } \\
\text { corriente potable en barrio El Talar. Ausencia de } \\
\text { protección de las cuencas hídricas de las Sierras Chicas. } \\
\text { Ausencia de estudios de la dinámica de los acuíferos } \\
\text { existentes. Falta de apoyo a los trabajos de } \\
\text { cooperativas, ONG y grupos movilizados. }\end{array}$ \\
\hline Villa Allende & Grupo Tacku & $\begin{array}{l}\text { Relevamientos del estado de la cuenca del arroyo Seco o } \\
\text { Chico. Realización de jornadas de "cartelería social". } \\
\text { Talleres con escuelas. Realización del anteproyecto de } \\
\text { Ordenamiento Territorial de la Reserva Hídrica y } \\
\text { Recreativa Natural Villa Allende. Participación en el } \\
\text { Consejo Municipal de Ambiente. }\end{array}$ & $\begin{array}{l}\text { Falta de una adecuada regulación de las reservas de las } \\
\text { Sierras Chicas. Reservas Naturales sin control municipal } \\
\text { o provincial. Superposición de ejidos y jurisdicciones } \\
\text { estatales (provinciales y municipales). Privatización y } \\
\text { desvío de arroyos. }\end{array}$ \\
\hline Saldán & $\begin{array}{l}\text { Fundación } \\
\text { Vertientes de } \\
\text { Saldán } \\
\text { Grupo Coyuyo }\end{array}$ & $\begin{array}{l}\text { Reforestación urbano-rural. Talleres en escuelas para dar } \\
\text { a conocer la reserva Saldán Inchín. Limpieza y cuidado } \\
\text { del arroyo Saldán. } \\
\text { Talleres de música autóctona con instrumentos de la } \\
\text { tierra. Aprovechamiento de flora nativa para la } \\
\text { producción de alimentos. }\end{array}$ & $\begin{array}{l}\text { Falta de un plan de manejo de la Reserva Saldán Inchin. } \\
\text { Agua contaminada y mala prestación del servicio de } \\
\text { agua en Barrio Portón de Piedra, Tejeda, Coop. } 2 \text { de } \\
\text { mayo y zonas aledañas. Contaminación del arroyo } \\
\text { Saldán. Falta de un comité de cuencas de las Sierras } \\
\text { Chicas }\end{array}$ \\
\hline La Calera & Grupo EsCalera & $\begin{array}{l}\text { Ordenamiento Territorial Participativo de la Reserva } \\
\text { Hídrica y Recreativa Natural Bamba. } \\
\text { Por su trayectoria, el trabajo iniciado en } 2005 \text { sirve como } \\
\text { base y sustento a muchas de las demás organizaciones de } \\
\text { las Sierras Chicas para su actividad. }\end{array}$ & $\begin{array}{l}\text { Urbanización y desmontes descontrolados. Falta de una } \\
\text { gestión ambiental adecuada del ambiente de montaña } \\
\text { de las Sierras Chicas. } \\
\text { Necesidad de aprobación del Plan de Ordenamiento } \\
\text { territorial de la cuenca del Arroyo Bamba. }\end{array}$ \\
\hline
\end{tabular}

Fuente: Entrevistas participantes y particulares a miembros de las organizaciones (Deón, 2015). 
universitarios como para la organización y el pueblo en general, tomando en cuenta una pluralidad de puntos de vista, demandas y posibles respuestas, todo ello considerado como aprendizaje social.

En la práctica, al poner en juego los diversos discursos que sostienen los agentes en el territorio, se puede avanzar en las discusiones y sacar nuevas conclusiones. Entre los actores locales, la gente de la MAYA, diferencia tres tipos de pobladores:

"están los "NYC" (nacidos y criados), los "VYQ" (venidos y quedados) y los profesionales que brindan apoyo técnico" 46 .

La tarea es encontrar puntos de encuentro para debatir las diferentes posturas sobre los intereses y necesidades colectivas de la comunidad, propiciando la participación en el espacio público y negociando soluciones consensuadas entre los diversos actores contrapuestos.

En aquellas situaciones donde hay un foco de disputa por un daño o afectación ambiental, se pone en discusión qué tipo de conocimiento será admitido como prueba y quiénes pueden ser los actores acreditados para generar ese conocimiento ${ }^{47}$.

De lo anterior se desprende que los conflictos por el agua, entendidos como un problema socioambiental, permiten al colectivo ir logrando mejores niveles de organización, visibilización, permanencia, participación $y$, de este modo, avanzar en acciones concretas. Entre ellas, la de proteger la fábrica de agua, que es la cuenca alta o de alimentación de los ríos y arroyos. La propuesta del equipo de investigación de apoyar a las comunidades en la concreción del corredor de reservas hídricas, dio sus frutos cuando en diciembre de 2014 se declaran los campos militares de Ascochinga como Reserva Natural de la Defensa ${ }^{48}$. A raíz de esto, en el comunicado anunciando este logro, la MAYA expresaba:

\footnotetext{
${ }^{46}$ Christine, integrante de la MAYA. La Granja, octubre de 2014. Esto lo habíamos detectado en el equipo de investigación, aunque nuestra clasificación fue más detallada. Así, realizamos una grilla de agentes de la zona baja, estableciéndose las siguientes categorías: Chavascates, Hippies, Serranos, Los del club, Primeros establecidos y neorrurales.

${ }^{47}$ Callon, 2001, 47-50.

48 http:/ / www. lavoz.com. ar/ ciudadanos/ crean-reserva-naturalen-sierras-chicas (Consulta realizada el 16 de mayo de 2015).
}

“... Como consecuencia de las sequías y la desmesura climática, los cordobeses ya hemos recorrido un largo camino en las demandas ambientales, lo que a la par creó una conciencia sobre la necesidad de preservar los bosques nativos como herramienta para cuidar ese bien amenazado que es el agua (...) La Reserva permitirá preservar a la captación de agua de Iluvia en la cuenca del Río J esús María. Insistimos, si algo sucedió en nuestra sociedad es que la ciudadanía comenzó a apropiarse de la democracia, que no se define solo por el acto de votar, sino por lo que le da fundamento: la participación y la transparencia en las cuestiones que son públicas, o sea de todos, tal como lo es el agua y el derecho constitucional a vivir en un ambiente sano" ${ }^{49}$.

La MAYA también luchó incansablemente para lograr que el trasvase de cuenca del río Tiú Mayú (afluente en la cuenca alta del río La Granja) hacia la localidad de La Falda, ubicada en la ladera occidental de la sierra dentro del valle de Punilla, se regularizara ante la DIPAS para, de este modo, compartir el agua en partes iguales. Del mismo modo, tendiendo siempre a la preservación de las cuencas, se realizaron denuncias sobre los incendios de 2012 y 2013. Realizan también presentaciones y trabajan conjuntamente cada vez que se organiza el Rally Internacional ya que pasa por la localidad y, según la gente de La Mesa, es perjudicial para nuestras fuentes de agua. Lo mismo respecto del uso de cuadriciclos y vehículos todo terreno:

"Son acciones pequeñas, pero que van sumando y nunca bajamos los brazos. Hacemos las presentaciones ante quien corresponda, la Municipalidad, el juzgado de J esús María, Ia DIPAS o el Ministerio de Ambiente. Estamos convencidos de que este trabajo va a ir dando sus frutos a mediano y largo plazo" 50.

Las últimas acciones conducidas por la MAYA fueron, entre otras, la presentación de un recurso de amparo, conjunto con la Coordinadora de Sierras Chicas, para la remediación de las cuencas después de las inundaciones de febrero de $2015^{51}$. Luego, en el caso del Río La Granja-Ascochinga, la presentación al Ministerio de Ambiente de la Provincia refiere a la exigencia de realizar estudios de impacto ambiental para la licitación del dragado y limpieza de los cauces. Asimismo, los integrantes de la Mesa están participando con la

\footnotetext{
${ }^{49}$ Gacetilla de Prensa de la MAYA. La Granja, 9 de septiembre de 2014.

50 J ulio, mayo de 2015.

51 Diario La Mañana de Córdoba, 22 de junio de 2015 (Consulta realizada el 16 agosto de 2015).
} 
delegación de Parques Nacionales en talleres informativos con los pobladores de las distintas localidades a fin de alcanzar la concreción del corredor hídrico en la cuenca alta de la vertiente oriental de las Sierras Chicas.

Las acciones que motoriza la MAYA vienen impulsadas por un trabajo conj unto con docentes y alumnos de la universidad. Creemos que estos recorridos compartidos son el modo de avanzar hacia la construcción de nuevas racionalidades sobre el ambiente, sus componentes y así poder contribuir a pensar otros modelos de desarrollo donde prime el valor de uso de los bienes de la naturaleza.

\section{CONSIDERACIONES FINALES}

Los intercambios realizados con la MAYA de la Granja, en términos de debates, permitieron entender los conflictos socioambientales como una arena de disputa donde se enfrentan intereses de agentes sociales que deben negociar, consensuar, proponer y poner en juego prácticas en un territorio que excede la cuenca del río y el límite del ejido municipal.

Así, hemos avanzado en la comprensión de que, en la disputa por los recursos naturales, su distribución, acceso y apropiación hay un interjuego de escalas espaciales de análisis que se deben considerar en las negociaciones y a lo largo del proceso de lucha.

También se incorporó la necesidad de analizar todo conflicto socioambiental más allá de la productividad de resultados concretos, como proceso de acciones en donde se superponen además de intereses y escalas, temporalidades diferentes.

La participación es una de las variables claves a considerar en este tipo de organizaciones. Al respecto, se advierte sobre la falta de participación de los vecinos, ya que en La Mesa convocan a reuniones para hablar de problemáticas comunes que afectan a todos y "siempre vienen los mismos" según sostuvo uno de los integrantes. A raíz de este comentario, sostenemos que lo propositivo no siempre logra adhesión y participación, que es una cuestión de hacer el camino lentamente, sin esperar resultados. Que, si en la acción política se emplean prácticas iguales y/ o similares a las de las instituciones a las cuales critican, la participación de la gente va a ser cada vez menor. Es necesario tener claro que las posiciones de los actores en el conflicto se van construyendo en el proceso mismo de despliegue de la acción colectiva y no previamente a partir de una posición unificada; esta dinámica es la que va generando formas organizacionales y lazos institucionales.

Las autoridades de gobierno y las autoridades científicas son las fuentes más importantes de autoridad, pero en ciertas ocasiones el movimiento ambientalista puede tener mayor reconocimiento cuando gana influencia política y social en determinada coyuntura. Se ha demostrado que estos agentes juegan un papel relevante en el proceso de valoración, filtración y construcción social que recorta una situación de la realidad y la transforma en problema ambiental ${ }^{52}$.

Pensar las problemáticas ambientales, la resolución de conflictos y las soluciones técnicas en un marco territorial y en forma participativa, posiblemente sea una estrategia de valor, no solo para aquellos agentes sociales que motorizan las demandas en el territorio, sino también para otros agentes como los gobiernos locales, que deberían propender a la búsqueda de soluciones consensuadas con la comunidad.

La experiencia que vienen llevando a cabo las organizaciones sociales de Sierras Chicas y que hemos tratado de resaltar en este artículo, nos invitan a pensar sobre las posibilidades de construir otros modelos de democracia, otras alternativas al desarrollo. Nos adherimos en esto a la propuesta de Arturo Escobar sobre las maneras de caminar hacia el posdesarrollo, donde las lógicas del lugar, los componentes culturales y las estrategias de sobrevivencia de las poblaciones locales, pasen a ocupar el centro de la escena:

\footnotetext{
“Aparecerán entonces espacios inesperados de creatividad y de resistencia, comprobaremos que los dispositivos del poder agotan su eficacia y que la globalización no completa sus ambiciones y promesas: son posibles 'mundos de otro modo'" 53 .
}

Para Escobar, estamos viviendo en una era de posdesarrollo, donde se imponen cambios de imaginarios políticos y sociales, se formulan nuevas preguntas o aparecen nuevas respuestas para viej as preguntas. Señala:

"El posdesarrollo significa la creación de un espacio/ tiempo colectivo en el cual:

\footnotetext{
52 Lezama, 2004.

53 Escobar, 2010.
} 
- $\quad$ se cuestione efectivamente la preeminencia del concepto de crecimiento económico y este como meta

- se propenda por formas de integración regional autónoma basadas en criterios ecológicos, de desarrollo autocentrado, a niveles subnacionales, nacionales, regionales y globales" 54 .

\section{BibLIOGRAFÍA}

Acosta, A. y Martínez, E. (Comps.) 2014: Desarrollo, postcrecimiento y Buen Vivir. Debates e interrogantes. Quito, Ediciones Abya-Yala.

Alimonda, H. (Coord.) 2002: Ecología política. Buenos Aires, CLACSO/CICCUS.

Alimonda, H. (Coord.) 2011: La naturaleza colonizada. Ecología política y minería en América Latina. Buenos Aires, CLACSO/CICCUS

Babiano-Amelibia, L. 2015: “Agua urbana: Mercantilización y resistencia social en España“, en Agua y Territorio, 6, 133-141. https: / / doi. org/ 10.17561/ at.v0i6. 2816

Bourdieu, P. 1991: El sentido práctico. Madrid, Taurus Ediciones.

Callon, M., Lascoumes, P. y Barthe, Y. 2001: Agir dans un monde incertain. Essai sur la démocratie technique. Paris, Seuil.

Carrizo, C. y Berger, M. 2013: “¿Qué es lo que puede el agua? Límites y posibilidades de las prácticas políticas para el acceso y defensa del agua como derecho en Argentina" en Agua y Territorio, 2, 11-23. https: / / doi. org/ 10.17561/ at. v1i2. 1339

Castoriadis, C. 2004: Sujeto y verdad en el mundo histórico-social. La creación humana I. Buenos Aires, FCE.

Castro, J. 2014: "Gobernabilidad y luchas por el agua. Un aporte al entendimiento de la lucha en las Sierras Chicas, Córdoba", en Cardinalis, 2, 137-153 (Disponible https: / / revistas. unc. edu. ar/ index. php/ cardi/ articl e/ view/7388, consulta realizada el 6 de enero de 2015).

Castro, J. E. 2014: “VI Reunión de la Red WATERLATGOBACIT "Agua, violencia y utopías. ¿Cuáles son las prioridades para construir una política hídrica igualitaria?", en Agua y Territorio, 4, 136-140. https:// doi. org/ 10.17561/ at.v1i4. 2172
Chiavassa, S., Deón, J., Ensabella, B. y Saavedra, C. 2012: "Los conflictos socioterritoriales en torno al uso del agua. El caso de la vertiente oriental de las Sierras Chicas de Córdoba". Ponencia presentada a la 9o Bienal del Coloquio de Transformaciones Territoriales, AUGM. San Miguel de Tucumán.

Chiavassa, S., Ensabella, B., Irazoqui, C., Llorens, S., Saavedra, C., Bustos, M. y Deón, J. 2013: "Dinámica social y territorial en relación a problemáticas del uso del agua. Estudio a nivel de cuencas en la vertiente oriental de las Sierras Chicas", en Cardinalis, 1, (disponible en http: / / revistas. unc. edu. ar/index. php/ cardi/ articl e/ view/7065, consulta realizada el 13 de diciembre de 2014).

Chiavassa, S., Llorens, S. y Irazoqui, C. 2009: "La producción del territorio a partir de los discursos y conflictos. La problemática del agua en las Sierras Chicas", en VI Jornadas de Encuentro Interdisciplinario de las Ciencias Sociales y Humanas en Córdoba. FFYH, UNC, Córdoba.

Deón, J. U. 2015: "Sierras Chicas, conflictos por el agua y el uso del suelo. Relaciones de poder en la gestión de cuencas. El caso de la cuenca del río Chavascate, Córdoba, Argentina", en Cardinalis, 4, 162-189. (Disponible en https:/ / revistas. unc. edu. ar/ index. php/ cardi/ articl e/ view/11804, consulta realizada el 20 de noviembre de 2015).

Eckstein, D. 2012: El agua un derecho humano. Cartilla de difusión. Córdoba (edición particular).

Escobar, A. 2005: Más allá del Tercer Mundo. Globalización y diferencia. Bogotá, Instituto Colombiano de Antropología e Historia-Universidad del Cauca.

Escobar, A. 2010: Una minga para el postdesarrollo: lugar, medio ambiente y movimientos sociales en las transformaciones globales. Lima, Universidad Nacional Mayor de San Marcos.

Guber, R. 1991: El Salvaje Metropolitano. Buenos Aires, Legasa.

Guber, R. 2001: La etnografía. Buenos Aires, Norma.

Guber, R. 2011: Etnografía: método, campo y reflexividad. 2a edición revisada y ampliada. Buenos Aires, Siglo XXI editores.

Gudynas, E. 2015: Derechos de la Naturaleza. Ética biocéntrica y políticas ambientales. Buenos Aires, edit. Tinta Limón.

Haesbaert, R. 2004: 0 mito da desterritorializaçao: do "Fim dos Territorios" a Multiterritorialidade. Rio de J aneiro, Ed. Bertrand Brasil.

Harvey, D. 1998: La condición de la posmodernidad. Barcelona, Gedisa.

\footnotetext{
54 Idem.
} 
Houtart, F. 2011: De los 'bienes comunes' al 'bien común' de la humanidad. Bruselas, Fundación Rosa Luxemburgo.

Lang, M. y Mokrani, D. (edits.) 2011: Más allá del desarrollo. Grupo Permanente de Trabajo sobre Alternativas al Desarrollo. Quito, Fundación Rosa Luxemburg-Abya Yala.

Leff, E. 2001: Epistemología Ambiental. México, Gedisa.

Lezama, J. L. 2004: La construcción social y política del medio ambiente. México, El Colegio de México.

Lopes de Souza, M. J . 1995: "O território: sobre espaço e poder, autonomia e desenvolvimento", en Elias de Castro, I., da Costa Gomes, P. C. y Lobato Corrêa, R. (orgs): Geografia: Conceitos e temas. Rio de J aneiro, Bertrand Brasil.

Merlinsky, G. (Comp.) 2013: Cartografías del conflicto ambiental en Argentina. Buenos Aires, ClacsoCiccus.

Palacio, A. A. et alt. 2010: Decidirnos a decidir. Experiencia sobre la gestación de la Reserva Natural Militar Estancia La Calera y la Reserva Hídrica y Recreativa Natural Bamba. Córdoba (Argentina), UNC-Aula de Montaña.

Piazzini Suárez, C. E. 2006: “Arqueología, espacio y tiempo: una mirada desde Latinoamérica", en Arqueología Suramericana, 2, 1, Universidad del Cauca, Colombia, 3-25

Porto Gonçalves, C. W. 2002: “Da geografia às geografias: um mundo em busca de novas territorialidades", en Ana Esther Ceceña y Emir Sader (coords.): La guerra infinita: Hegemonía y terror mundial. Buenos Aires, CLACSO, 217-256.
Porto Gonçalves, C. W. 2004: O desafio Ambiental. Os Porquês da desordem mundial, mestres explicam a globalização (Sader, E. comp.). Rio de Janeiro, Record.

Porto Gonçalves, C. W. 2014: “Un mundo en busca de otras territorialidades", en Alfilo, 47. FFyH, UNC, septiembre (disponible en http: / / www.ffyh. unc. edu. ar/ alfilo/ un-mundo-enbusca-de-otras-territorialidades/, consulta realizada el 20 de noviembre de 2015).

Raffestin, C. 1993: Por uma geografia do poder. São Paulo, Atica.

Rodríguez Bilella, P. 2008: "Transformaciones globales, modos de vida y desarrollo rural", en P. Rodriguez Bilella y E. Tapella: Transformaciones globales y territorios. Buenos Aires, La Colmena.

Santos, M. 1996: A Natureza do Espaço. Técnica e Tempo / Razão e Emoção. São Paulo, Hucitec.

Soja, E. 1993: Geografías Pós-Modernas. A reafirmaçao do Espaço na teoria social crítica. Rio de Janeiro, J orge Zahar Editor.

Soja, E. 2004: Lo macro, lo mezzo, lo micro: "nosotros hemos producido nuestros espacios y podemos cambiarlos (disponible en http:// www.cafedelasciudades.com. ar/ politica_22 . htm, consulta realizada el 20 de noviembre de 2015).

Taylor, S. J. y Bogdan, R. 1996: Introducción a los métodos cualitativos de investigación. Buenos Aires, Paidós. 